\title{
Simulation of $\mathrm{C}$ and $\mathrm{N}$ in the Soil Microbial Biomass after Straw Incorporation into Soil
}

\author{
Francesco Agostini*, Paul Sholefield*
}

*ADAS Wergs Rd Wolverhampton Midlands WV6 8TQ

Received: 1 November 2003. Accepted: 21 March 2005

\begin{abstract}
Straw incorporation into soil seems to limit $\mathrm{N}$ leaching as well as improving soil structure and contributing to $\mathrm{C}$ storage in soil. A better understanding of its effect on the dynamics of soil $\mathrm{N}$ can be reached using a model simulating $\mathrm{C}$ and $\mathrm{N}$ contents in soil biomass. A simple model has been developed modifying the sub-routine of crop residue decomposition implemented in the SUNDIAL package. The updated model calculates daily $\mathrm{N}$ and $\mathrm{C}$ in microbial biomass, using an increased number of pools with different decomposition rates in order to simulate the differentiate decomposition carried out by soil fungal and bacterial populations. The model has been calibrated using results of a laboratory experiment, and then validated using published data from a field experiment on straw incorporation. In both cases soil moisture content and temperature has not been taken into account to carry out a more robust evaluation. The new model, which uses composite pools instead of single pools to describe the residual and the microbial biomass pools, can more accurately predict $\mathrm{C}$ and $\mathrm{N}$ contents in microbial soil biomass shortly after straw incorporation; however it is still inaccurate in simulating longer scenarios (365 days). The work presented here shows how even a semi-empirical model such as SUNDIAL when properly modified can simulate the effect of straw incorporation, however further work is required to determine a possible microbial and or chemical justification for the empirical splitting of the decomposition pool.
\end{abstract}

Key-words: Microbial soil biomass, modelling, $\mathrm{N}$ and $\mathrm{C}$ cycles, straw incorporation.

\section{Introduction}

The ban on straw burning in the UK has increased the practice of straw incorporation. This could result in a significant increase in the C stocks of cultivated soils (Nicholson et al., 1997). Clearly, this increase has a strong effect on $\mathrm{N}$ (N) cycling (Wheatly et al., 1991), and among the various $\mathrm{N}$ pools the total soil biomass $\mathrm{N}$ is strongly affected by the increased C. (Ocio et al., 1991a and 1991b). Numerous studies suggest that straw incorporation could reduce nitrate leaching by promoting inorganic $\mathrm{N}$ immobilisation (Powlson et al., 1985; Jarvis et al., 1989; Powlson, 1990; Bhogal et al., 1997). Consequently a better understanding of $\mathrm{N}$ dynamics following straw incorporation is needed to fully explain the above phenomena. Over the past
20 years, modelling has emerged as an essential tool to investigate the dynamics of $\mathrm{C}$ and $\mathrm{N}$ in soil-crop systems (Jenkinson \& Rayner, 1977; Whitmore, 1993, Molina and Smith, 1997; Gabrielle et al., 2000). This approach has been often, if not mainly, focused on the role of soil biota as the main mediator in soil nutrient cycles. Then the available literature is so large that numerous and extensive reviews have been written by several authors on the main models so far developed (Smith et al., 1998). Paustian (1991) in his review distinguishes between "processes-oriented" models and "organism-oriented" models and underlines the needs to relate the theoretical pools of the models to measurable organic matter pools. Most of the models so far developed are "processes-oriented"

\footnotetext{
* Corresponding Author: E-mail address: francesco.agostini@adas.co.uk
} 
models, which simulate soil processes as energy and or matter transformations. They treat the soil microbial population as a generic undifferentiated component, this prevents the simulation differenting between activities of the different groups of micro organism. These models can describe this component as a single pools or as a composite pools. Their parameters are derived often from field experiments therefore are simpler to be calibrated for being used in new site. All the more commonly used soil $\mathrm{C}$ and $\mathrm{N}$ models belong to this category, as NCSOIL (Molina et al., 1983), SOILN (Begström et al., 1991), ANIMO (Rijtema and Kroes, 1991), DAYSI (Hansen et al., 1991), CENTURY (Kelly et al., 1997) and Rothamsted C Model (Coleman et al., 1997).

In contrast the 'organism-oriented' models simulate flows of energy and matter through different groups of soil microorganisms. These, due to the complexity of soil biota and its high variability according soil typology and clime, are rarely designed and poorly used, especially as predictive tools (Smith et al., 1998). Finally some "processes-oriented" model, with composite pools which try to model measured fraction of soil organic matter, providing a representation of soil microbial turnover can be seen as a hybrid between the above mentioned model categories (Smith et al., 2002). The last approach can provide successful simulation of the effect of straw incorporation into soil on $\mathrm{N}$ dynamics, as shown in the PASTIS/CANTIS model, which describes the soil microbial biomass as two pools respectively representing zymogenous and autochthonous biomass (Garnier et al., 2003). In this work we have focused on the effect of straw incorporation on soil microbial biomass, because a model that explicitly describes microbial dynamics can provide a more realistic representation of the soil system (Grant et al., 1993a), and because nutrients are rapidly cycled through the microbial biomass pool. The microbial biomass simulation sub-routine from the SUNDIAL model (Bradbury et al.,1993) was used as the basis of a laboratory model to simulate the decomposition of straw in the soil and how it can affect soil $\mathrm{N}$ dynamics. Previous simulations using the single pool model of soil organic matter implemented within the current version of SUNDIAL have shown a poor fit with biomass $\mathrm{N}$ measured in straw incorpora- tion experiments. Short term observations following straw incorporation (Amato et al., 1984; Ocio et al., 1991a) suggest the need to modify the compartments simulating biomass and crop residue pools. Therefore the aim of the presented work was to modify the SUNDIAL sub routine with a composite pools model of soil organic matter and to evaluate its capability to simulate biomass $\mathrm{N}$ variation due to straw incorporation. The design of the composite pools model has been carried out without any correction for soil parameters such as moisture or temperature, in agreement with the suggestion of Smith et al. (2002) for a robust modelling of soil organic matter.

\section{Materials and methods}

\subsection{Experimental data}

One data set from published laboratory incubation experiments (laboratory) was used to calibrate the composite pools model and one data set from a published field experiment on straw incorporation (field) gave the dataset for its validation.

In the laboratory experiment (Ocio et al., 1991b) straw was added immediately before the incubation. $50 \mathrm{~g}$ of soil from the Rothamsted Highfield experiment (silty clay loam, with $1.71 \% \mathrm{C}$ and $0.117 \% \mathrm{~N}$ ) was incubated at $20^{\circ} \mathrm{C}$ with $250 \mathrm{mg}$ of straw $(41.3 \% \mathrm{C}$ and $0.46 \% \mathrm{~N})$ for 2, 5, 10, 25 and 50 days. Biomass $\mathrm{N}$, biomass $\mathrm{C}$ and $\mathrm{CO}_{2} \mathrm{C}$, released during the incubation of soil samples, were measured (Brookes et al., 1985, Jenkinson \& Powlson, 1976). The laboratory data set was used to verify the new model structure with composite pools of organic matter and to set the pool parameters.

The field experiment (Ocio et al., 1991a) was carried out in Long Hoos Fallow at Rothamsted. (silty clay loam with $1.23 \% \mathrm{C}$ and $0.12 \% \mathrm{~N}$, $\mathrm{pH} 7.3$ and a water holding capacity of $34 \mathrm{~g}$ on $100 \mathrm{~g}^{-1}$ of soil, measured at $10 \mathrm{hPa}$ ), the surface was cleared of weed and ploughed to $23 \mathrm{~cm}$ depth. After the plough $10 \mathrm{t} \mathrm{ha}^{-1}$ of straw $(43.5 \%$ $\mathrm{C}$ and $0.91 \% \mathrm{~N}$ ) was incorporated to $15 \mathrm{~cm}$ depth in plots of $1 \mathrm{~m}^{-2}$, during the late October 1987. The soil was regularly weeded in order to keep it clear of vegetation. The field soil was sampled weekly from day 7 to day 363 , and biomass $\mathrm{N}$ was measured with the same method- 
Original mineralisation routine: Single pools New mineralisation routine: Composite pools
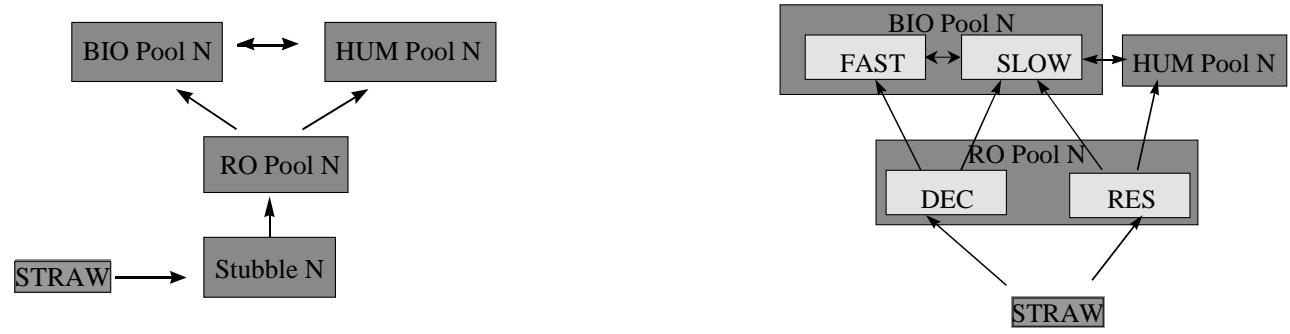

BIO: Biomass

HUM: Humus

RO: Residues

FAST: Biomass with fast decomposition rate

SLOW: Biomass with slow decomposition rate

DEC: Decomposable portion of residues

RES: Resistant portion of residues

Figure 1. Diagram of N Pools and fluxes, as affected by straw incorporation in the single pools model of SUNDIAL, (left draw), and in the composite pools version (right draw).

ology applied in the laboratory experiment (Brookes et al., 1985).

\subsection{Model development}

The development of the model has been carried out in three steps:

A) Development of a new model with composite pools splitting the crop residual and microbial biomass pools. B) Selection of relevant parameters of the composite pools model according the literature and their calibration using data on biomass $\mathrm{N}$ and $\mathrm{C}$ and $\mathrm{CO}_{2}-\mathrm{C}$ release from a laboratory incubation experiment on straw already published. C) Validation of the composite pools model through comparing the simulation of the increase in biomass $\mathrm{N}$ due to straw incorporation into a clay loam soil observed during a field experiment carried out by the composite with one carried out by the original single pool model.

SUNDIAL is a $\mathrm{N}$ turnover model that describes soil organic matter (SOM) dynamics on a weekly basis. It includes three organic matter pools: crop residue (RO), biomass (BIO) and humus (HUM) (Figure 1, left drawing). After the implementation of the three single pools and of their turnover equations in a spreadsheet, simulations of total biomass $\mathrm{N}$ were carried out using data sets from literature (data not presented). The predicted data were close only to initial observed data. The comparison of the changes in the time course of the predicted values with that of the observed values suggested that the crop debris pools and the biomass pools should be modelled as two different pools each with different compositions and decomposition rates. The splitting of microbial biomass in different pools is justified by the findings of a number of authors (Molina et al., 1983; Johnson, 1987; Nicolardot \& Molina, 1994). The very same approach has been followed in a much more complex model already validated as good predictive tools for simulating the effect of straw incorporation into the soil (Garnier et al., 2003). Using modifications to the original SUNDIAL equations I built a composite pools model which included five pools of soil organic matter: two describing crop residues, two describing the microbial biomass and only one, describing humus (Figure 1, right drowing). The equations driving the exchange of $\mathrm{C}$ and $\mathrm{N}$ between the pools are given in Table 1 and 2, they derive from the main equation for RO, HUM and BIO pools described by Bradbury et al. (1993).

At this stage no corrections of the turnover and decomposition order and rate due to soil moisture and temperature were implemented. This allows a more robust test of the new composite pools model as suggested by Smith et al. (2002). The time step for decomposition was set to a daily as opposed to the weekly time step used in the original model. The biomass and crop 
Table 1. Model of carbon fluxes in the composite pools model.

$$
\begin{aligned}
& D_{1}=D_{0} * e^{-d} \\
& R_{1}=R_{0} * e^{-r} \\
& F_{1}=a D_{0}\left(1-e^{-d}\right)-(1-a) F_{0}\left(1-e^{f}\right) \\
& S_{1}=b-D_{0}\left(1-e^{-d}\right)+R_{0}\left(1-e^{-r}\right)+F_{0}\left(1-e^{f}\right)+H_{0}\left(1-e^{-h}\right)-(1-b F) S_{0}\left(1-e^{s}\right) \\
& H_{1}=c \quad R_{0}\left(1-e^{-r}\right)+S_{0}\left(1-e^{s}\right)-(1-c) H_{0}\left(1-e^{-h}\right) \\
& C O_{2}=(1-(a+b))\left[D_{0}\left(1-e^{-d}\right)+F_{0}\left(1-e^{f}\right)\right]+(1-(b+c))\left[R_{0}\left(1-e^{-r}\right)+S_{0}\left(1-e^{s}\right)+H_{0}\left(1-e^{-h}\right)\right]
\end{aligned}
$$

Pools

$\mathrm{F}=$ Fast Biomass; $\mathrm{S}=$ Slow Biomass; $\mathrm{H}=$ Humus; $\mathrm{D}=$ Decomposible Residue;

$\mathrm{R}=$ Resistant Residue

Parameters

$\mathrm{f}=$ decomposition rate of $\mathrm{F}$

$\mathrm{s}=$ decomposition rate of $\mathrm{S}$

$\mathrm{h}=$ decomposition rate of $\mathrm{H}$

$\mathrm{d}=$ decomposition rate of $\mathrm{D}$

$\mathrm{r}=$ decomposition rate of $\mathrm{R}$

$\mathrm{a}=$ retained proportion of $\mathrm{F}$

$\mathrm{b}=$ retained proportion of $\mathrm{S}$

$\mathrm{c}=$ retained proportion of $\mathrm{H}$

Subscripts refer to the time of simulation:

$0=$ time 0

$1=$ after 1 day
Table 2. Model of nitrogen fluxes in the composite pools model.

$$
\begin{aligned}
& D_{N 1}=u D_{1} \\
& R_{N 1}=v R_{1} \\
& S_{N 1}=y S_{1} \\
& H_{N 1}=z H_{1} \\
& F_{N 1}=x F_{1} \\
& N_{\min }=(u-(x a \\
& +(y-(y b+z c)) \\
& \text { Pools } \\
& \mathrm{F}_{\mathrm{N}}=\text { Fast Biom } \\
& \text { sable Residue, } \\
& \text { Parameters } \\
& \mathrm{u}=\mathrm{N} / \mathrm{C} \text { of } \mathrm{D} \\
& \mathrm{v}=\mathrm{N} / \mathrm{C} \text { of } \mathrm{R} \\
& \mathrm{x}=\mathrm{N} / \mathrm{C} \text { of } \mathrm{F} \\
& \mathrm{y}=\mathrm{N} / \mathrm{C} \text { of } \mathrm{S} \\
& \mathrm{z}=\mathrm{N} / \mathrm{C} \text { of } \mathrm{H}
\end{aligned}
$$$$
N_{\text {min }}=(u-(x a+y b)) D_{0}\left(1-e^{-d}\right)+(v-(y b+z c)) R_{0}\left(1-e^{-r}\right)+(x-(x a+y b)) F_{0}\left(1-e^{-f}\right)
$$$$
+(y-(y b+z c)) S_{0}\left(1-e^{-s}\right)+(z-(y b+z c)) H_{0}\left(1-e^{-h}\right)
$$

$\mathrm{F}_{\mathrm{N}}=$ Fast Biomass $\mathrm{N}, \mathrm{S}_{\mathrm{N}}=$ Slow Biomass $\mathrm{N}, \mathrm{H}_{\mathrm{N}}=$ Humus $\mathrm{N}, \mathrm{D}_{\mathrm{N}}=\mathrm{N}$ in Decomposable Residue, $\mathrm{R}_{\mathrm{N}}=\mathrm{N}$ in Resistant Residue.

Subscripts refer to the time of simulation:

$0=$ time 0

$1=$ after 1 day residues pools were split into two sub-compartments each with different daily rates of decomposition and turnover. This design was an attempt to describe straw decomposition and biomass turnover by the different microbial and fungal populations, splitting the distinct composition and decomposition path- ways. It also avoids the need to set pool sizes with respect to the specific composition of crop residues. In fact such pool would require a large number of additional analytical parameters to calibrate the model. (Molina et al., 1983; Sallih and Pansu, 1993; Grant et al., 1993b). 


\subsection{Calibration and validation}

The modified model was implemented in a spreadsheet; the decomposition rates and the partition coefficient between the easily decomposed and the resistant straw were set using the data set from the laboratory experiment. The partition coefficient and the parameters were set by minimising the least square difference between the observed and simulated values (Table 3). This first evaluation carried out through a laboratory experiment focused on $\mathrm{N}$ and $\mathrm{C}$ contents in the microbial soil biomass. Their better simulation after straw addition carried out by the multi pools model (detailed in the "Model development" section of Results and Discussion) provided confidence in the approach and new design of the organic matter pools. Therefore the composite pools model was then implemented within the source code of SUNDIAL model and further assessed using the data of Biomass $\mathrm{N}$ measured from the soil sample collected from the field experiment after straw incorporation. A simulation was carried out also with the single pool model, running with a weekly step, in order to compare the performance of the two models. The parameters calibrated through the simulation of the laboratory data sets were kept for both simulations of the field dataset (Table 3). Both simulations were carried out also keeping the decomposition rate and the order of decompositions constant independently from soil moisture and temperature (Smith et al., 2002).

\subsection{Statistics}

The statistics RMSE, E, r (Smith et al. 1996) and
Table 3. Parameters resulting from the calibration of composite pools model done by the data of the laboratory experiment.

\begin{tabular}{|c|c|c|}
\hline \multicolumn{3}{|c|}{$\begin{array}{l}\text { After calibration (minimised } \\
\text { least square difference between } \\
\text { observed and simulated) }\end{array}$} \\
\hline $\begin{array}{l}\text { Partition Coefficient } \\
\text { between decomposable } \\
\text { and resistant portion } \\
\text { of residues: } 43 \%\end{array}$ & & $50 \%$ \\
\hline \multicolumn{3}{|l|}{ Rates: } \\
\hline Decomp. & 0.1 & 0.05 \\
\hline Res. & 0.01 & 0.01 \\
\hline Fast & 0.004 & 0.009 \\
\hline Slow & 0.02 & 0.001 \\
\hline Hum & 0.00003 & 0.00003 \\
\hline \multicolumn{3}{|l|}{ Fractions } \\
\hline $\mathrm{a}$ & 0.1 & 0.1 \\
\hline $\mathrm{b}$ & 0.1 & 0.1 \\
\hline $\mathrm{c}$ & 0.1 & 0.1 \\
\hline \multicolumn{3}{|l|}{ Rates N/C } \\
\hline $\mathrm{u}$ & 0.2 & 0.2 \\
\hline $\mathrm{v}$ & 0.04 & 0.04 \\
\hline $\mathrm{x}$ & 0.15 & 0.2 \\
\hline $\mathrm{y}$ & 0.2 & 0.2 \\
\hline $\mathrm{Z}$ & 0.1 & 0.1 \\
\hline
\end{tabular}

LOFIT (Whitemore, 1991) were calculated for the simulation of the biomass $\mathrm{N}$ from field experiment. They were used to quantify any improvements associated with the composite pools model, (Table 4). Root mean square error (RMSE) measures the simulation error; the lower it is, the better is the simulation. It must be considered with its confidence limit (RMSE_95), if the RMSE is smaller than RMSE_95, then the simulations fall within the $95 \%$ confidence interval of the measurements. Relative error (E)

Table 4. Evaluation indices, (Smith et al., 1996) calculated by comparing the simulations carried out using the composite pools model and single pools model from the SUNDIAL with measured microbial biomass $\mathrm{N}$ from the field experiment.

\begin{tabular}{lcccccc}
\hline Model & $\mathrm{r}$ & RMSE & RMSE_95 & E & E_95 & LOFIT (kg ha $\left.^{-1}\right)^{2}$ \\
\hline Composite pools & $0.94^{* *}$ & 20.56 & 6.99 & 1.18 & 5.75 & 12355 \\
Single pools & $0.61^{*}$ & 27.01 & 6.99 & 5.02 & 5.75 & 21318
\end{tabular}

RMSE $=(100 / \bar{O}) \sqrt{ }\left(\sum\left(P_{i}-O_{i}\right)^{2} / \mathrm{n}\right)$, where $\bar{O}$ is the mean of the observed measures, $P_{i}$ is the predicted value by the simulation, $O_{i}$ is the actual observed (measured) value, $\mathrm{n}$ is the number of observed values.

RMSE_95 $\left.=(100 / \bar{O}) \sqrt{ }\left(\sum_{(n-2) 95 \%} X S_{e}(i)\right)^{2} / \mathrm{n}\right)$, where is the Student's t distribution with n-2 degrees of freedom and a two-tailed $P$-value of 0.05 , is the standard error of (i) measure.

$\mathrm{E}=(100 / \mathrm{n}) \sum\left(O_{i}-P_{i}\right) / O_{i}$.

E_95 $=(100 / \mathrm{n}) \sum\left(t_{(n-2) 95 \%} X S_{e}(i)\right) / O_{i}$.

LOFIT $=\sum m_{j}\left(\bar{O}_{j}-P_{j}\right)^{2}$, where $m_{j}$ is the number of replicates of each $j$ th measures, $P_{j}$ is the simulation of the $j$ th measures, $\bar{O}_{j}$ is the mean of all $j$ th measures. Its significance determined with an F-test, shows if the simulation error is greater than the experimental error of observed data.

**High Significant $(P<0.001)$; *Significant $(P<0.005)$. 

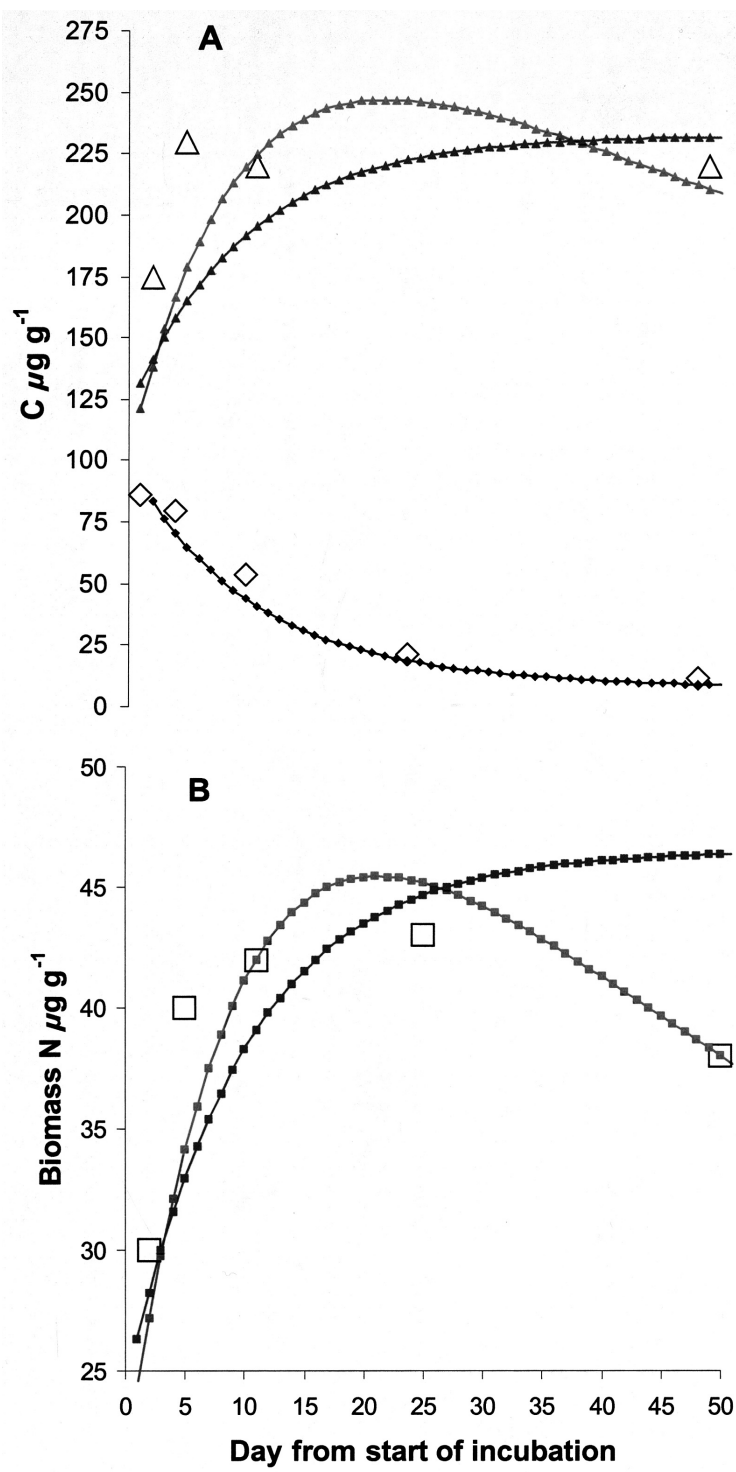

Figure 2. Biomass $\mathrm{C}$, loss $\mathrm{CO}_{2}-\mathrm{C}(\mathrm{A})$ and biomass $\mathrm{N}$ (B) measured during the laboratory experiment or daily simulated by the composite pools (red line) and by the single pool model (blue line). Biomass $C(\triangle)$, simulated biomass $\mathrm{C}(\boldsymbol{\Delta})$, loss $\mathrm{CO}_{2}-\mathrm{C}(\diamond)$, simulated $\mathrm{CO}_{2}-\mathrm{C}(\diamond)$, biomass $\mathrm{N}$ $(\square)$, simulated biomass N ( $\square)$.

is a measure of the relative bias in the total difference between simulations and measurements, its confidence limit is E_95, which is the relative error calculated on a deviation of $95 \%$ confidence interval of the measurements, the significance of $\mathrm{E}$ can be determined by comparing the two. If E > E_95, this means that the bias of the simulation is greater than the estimated possible bias in measurements. The lack of fit
(LOFIT) allows us to distinguish the experimental error from the error of the model simulations.

\section{Results and discussion}

\subsection{Model development}

The parameters of the new model were set by fitting to biomass $\mathrm{C}$ and $\mathrm{N}$ measurements from the laboratory experiment, Table 3 . The parameter values are of similar magnitude to those proposed for residues of winter wheat in other decomposition first order equations (Amato et al., 1984; Gilmour et al., 1985; Moorhead et al., 1988; Gilmour et al., 1998). They produced a good qualitative fit between measurements and simulation for both $\mathrm{C}$ and $\mathrm{N}$ pools, whereas the simulations carried out by the single pool model (blue lines) fail to follow the decrease of $\mathrm{C}$ and $\mathrm{N}$ measured at the end of the incubation period (Figure 2, A and B).

However, the composite model initially overestimates the $\mathrm{CO}_{2}-\mathrm{C}$ loss (Figure $2 \mathrm{~A}$ ). This might be attributed to the lack of any correction of temperature and moisture content at this stage.

3.2 Validation of New Model with composite pools within the source code of SUNDIAL

An evaluation of the improvement due to the implementation and setting of the new structure in the model was carried out comparing simulations of microbial biomass $\mathrm{N}$ generated by straw incorporation during the field experiment done by the single pools model with that one predicted by the composite pools model (Figure 3 ).

The daily model with composite pools simulates biomass more accurately than the weekly model with single pools, especially the $\mathrm{N}$ peak, which occurs in the first 28 days after straw incorporation. For the following 86 days however, the model under-predicted the biomass $\mathrm{N}$ value and then over-predicted it. This can be partially justified with the limit of incubation tests carried out in the laboratory to simulate field condition and used to calibrate the model, as several works demonstrated the $\mathrm{N}$ mineralised in field condition is less than the $\mathrm{N}$ mineralised in simulated laboratory conditions (Delphin, 2000). The measurements showed a increase in $\mathrm{N}$ in the biomass pool, which happens in the 3-4 weeks after the incorporation, followed by a 


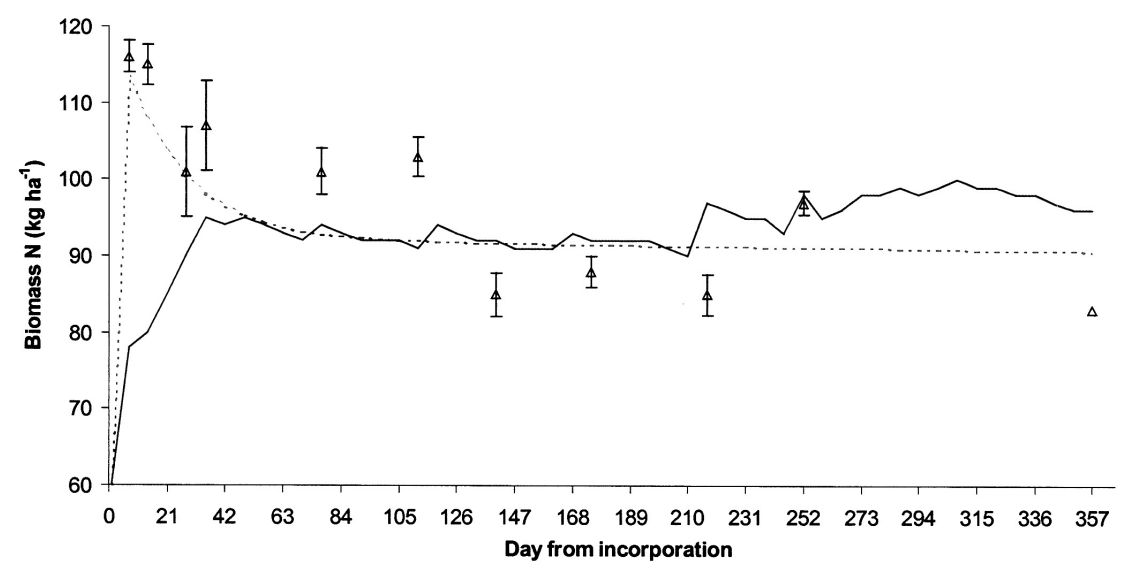

Figure 3. Biomass $\mathrm{N}$ in the 0 $20 \mathrm{~cm}$ soil layer after straw incorporation during the field experiment, measured $(\boldsymbol{\Delta})$, simulated by the single pools model $(-)$, simulated by the composite pools model (-). Error bar on three replicated measures. quick decrease. This rapid change in the $\mathrm{N}$ content of the biomass was probably due to the addition of $\mathrm{C}$ to soil by the straw. This effect disappeared after 3 months.

The statistical indices (Table 4) show a better simulation carried out with the daily step composite pools models, with a much bigger and highly significant regression coefficient $(0.94, P$ $<0.01$ ) and a relative error (E) smaller and (after having compared as E with the E_95 value), indicating that the simulation bias is smaller than the possible measures bias. The lack of fitting (LOFIT) also decreases by nearly 50\%. This simulation result confirms the suggestion of other workers, (Henriksen \& Breland, 1999), that the decomposition rate constant obtained from laboratory experiments can be used to simulate field trials even without any temperature and moisture content correction. However there is still plenty of room for further improvements in the simulation (the RMSE is only slightly decreased, from 27.01 with the single pools to 20.56 with the composite pools) which could be achieved using calibration data sets from laboratory experiments under conditions of straw degradation closer to those in the field. In fact the soil in the laboratory tests was probably drier and at higher temperature than that in the field at the time of the incorporation. The simulations carried out during the model development demonstrate the following:

- the simulated $\mathrm{N}$ is strongly affected by the splitting of the biomass pool;

- a daily composite pools model can better simulate the observed increases in $\mathrm{N}$ following straw incorporation then a weekly single pool model. This modification is in agree- ment with the more recent suggestions of workers on SUNDIAL (Smith et al., 2002). However pool splitting is only one possible strategy available to improve organic matter decomposition models;

- laboratory soil incubations can provide data to calibrate model simulation $\mathrm{C}$ and $\mathrm{N}$ turnover under field conditions, as already described in previous works (Garnier et al., 2003);

- further development of the model is needed to improve simulation of the effect on soil $\mathrm{N}$ dynamics of straw incorporation in short or medium term. This should be realised by splitting not only the plant residual pool and the biomass pool but the humus pool as well (Smith et al., 2002). Ideally all the sub pools should be equivalent to measurable organic matter components of the soils, however this path can lead to models demanding a large number of parameters difficult and expensive to calibrate. Finally, after the evaluation phase, the effect of soil conditions, such as temperature and soil moisture should be taken into account within the modelling of the whole soil $\mathrm{N}$ dynamics to tune the composite pools model through the addition of corrective parameters within the turnover equations.

\section{Conclusions}

A multi component model of the $\mathrm{N}$ cycle in the soil after straw incorporation has been developed and validated. The original routine, using single decomposition pools and single decom- 
position rates, was not able to simulate the $\mathrm{N}$ and $\mathrm{C}$ increase in the microbial biomass pool, occurring in the 3-4 weeks after straw incorporation (Ocio et al., 1991a and 1991b). The improved routine splits the original biomass and crop residue pools into two sub pools each with discrete decomposition rates. The new design aims to describe straw decomposition by the different microbial and fungal populations, keeping the simplicity of SUNDIAL.

A robust evaluation carried out after a calibration through data obtained by soil incubation confirmed that the new model is not only able to fit the data from a laboratory experiment, but can also improve the simulation of $\mathrm{N}$ dynamics following straw incorporation in the field. The composite pools can simulate the processes involved in $\mathrm{N}$ release from the decomposable and the residual fraction of organic matter added to the soil and its fixation in the microbial biomass of the soil. However, the pool partitioning is empirical and with few links with soil biological findings.

A functional model such as SUNDIAL, which requires few input data, is able to simulate the complex process of the residue decomposition in the soil. Further investigations and validations should be done to asses if other approaches, such as single pool component with a variable decomposition rate, can give better simulation requiring the same or even less input data (Yang and Janssen, 2000).

\section{Acknowledgements}

This research was supported by an EU grant in the frame of Training and Mobility of Researchers Programme. The authors thank Jo Smith and Nicky Bradbury for their help in the design of the composite pools model, Benoit Gabriel for its implementation within the FORTRAN source code of SUNDIAL, Jim Webb for the revision of the manuscript.

\section{References}

Amato M., Jackson R.B., Butler J.H.A., Ladd J.N. 1984. Decomposition of plant material in Australian soils: II. Residual organic $14 \mathrm{C}$ and $15 \mathrm{~N}$ from legume plant parts decomposing under field and laboratory conditions. Aust. J. Soil Res. 22:331-341.

Begström L., Johnsson H., Torstensson G. 1991 Simulation of soil N dynamics using the SOILN model. Fertilizer Research 27:181-188.
Bhogal A., Young S.D., Sylvester-Bradley R. 1997. Straw incorporation and immobilisation of spring-applied N. Soil Use and Management. 13:111-116.

Bradbury N.J., Whitemore A.P., Hart P.B.S., Jenkinson D.S. 1993. Modelling the fate of $\mathrm{N}$ in crop and soil in the years following application of N15 labelled fertiliser to winter wheat. J. Agric. Sc. Camb. 12:363-379.

Brookes P.C., Krangt J.F., Powlson D.S., Jenkinson D.S. 1985. Chloroform fumigation and the release of soil $\mathrm{N}$ : A rapid direct extraction method for measuring microbial biomass $\mathrm{N}$ in soil. Soil Biol. and Biochem., 17:837-842.

Coleman K., Jenkinson D.S., Crocker G.J. 1997 Simulating trends in soil organic $\mathrm{C}$ in long-term experiments using RothC_23.6. In: Smith P., Powlson D.S., Smith J.U., Elliot E.T. (eds.): Evaluation and comparison of Soil Organic Matter Models Using Datasets from Seven Long-Term Experiments. Special Issue of Geoderma, 81:29-44.

Delphin J.E. 2000. Estimation of $\mathrm{N}$ mineralization in the field from an incubation test and from soil analysis Agronomie 20:349-361.

Gabrielle B., Agostini F., Donatelli M. 2000. Limits to the accuracy of the water component of a decisionsupport-oriented agronomic model. Italian J. Agron., 3:87-99.

Garnier P., Neel C., Aita C., Recous S., Lafolie F., Mary B. 2003. Modelling $\mathrm{C}$ and $\mathrm{N}$ dynamics in a bare soil with and without straw incorporation. Eur. J. of Soil Science, 54:555-568.

Gilmour J.T., Clark M.D., Sigua G.C. 1985. Estimating net $\mathrm{N}$ mineralization from $\mathrm{C}$ dioxide evolution. Soil Sci. Soc. Am. J., 49:1398-1402.

Gilmour J.T., Mauromoustakos A., Gale P.M., Norman R.J. 1998. Kinetics of Crop Residue Decomposition: Variability among Crops and Years. Soil Sci. Soc. Am. J., 62:750-755.

Grant R.F., Juma N.G., McGill W.B. 1993a. Simulation of C and $\mathrm{N}$ transformation in soil: microbial biomass and metabolic products. Soil Biol. Biochem., 25:1331-1338.

Grant R.F., Juma N.G., McGill W.B. 1993b. Simulation of $\mathrm{C}$ and $\mathrm{N}$ transformations in soil: mineralization. Soil Biol. Biochem., 25:1317-1329.

Hansen S., Jensen H.E., Nielsen N.E., Svendsen H. 1991 Simulation of $\mathrm{N}$ dynamics and biomass production in the winter wheat using the Danish Simulation model DAISY. Fertilizer Research, 27:245-259.

Henriksen J.H., Breland B.B. 1999. Composition of crop residues in the field: evaluation of a simulation model developed from microcosm studies. Soil Biol. Biochem., 3:1423-1434.

Jarvis S.C., Barraclough D., Unwin R.J., Royle S.M. 1989. Nitrate leaching from grazed grassland and after straw incorporation in arable soils. In: Germon J.C. (ed.): Management Systems to Reduce Impact of Nitrates. Elsevier Applied Science, London and New York, 110-125. 
Jenkinson D.S., Powlson D.S. 1976. The effects of Biocidal treatments on metabolism in soil. V: method for measuring soil Biomass. Soil Biol. Biochem., 8:209213.

Jenkinson D.S., Rayner J.H. 1977. The turnover of soil organic matter in some of the Rothamsted classical experiments. Soil Science, 123:298-303.

Kelly R.H., Parton W.J., Crocker G.J., Grace P.R. 1997 Simulating trends in soil organic $\mathrm{C}$ in long-term experiments using the CENTURY model. In: Smith P., Powlson D.S., Smith J.U., Elliot E.T. (eds.): Evaluation and comparison of Soil Organic Matter Models Using Datasets from Seven Long-Term Experiments. Special Issue of Geoderma, 81:29-44.

Johnson H. 1987. Simulated N dynamics and losses in a layered agricultural soil. Agric. Ecosys. Environ., 18:333-356.

Moorhead K.K., Graetz D.A., Reddy K.R. 1988. Mineralization of $\mathrm{C}$ and $\mathrm{N}$ from freeze- and oven- dried plant material added to soil. Soil Sci. Soc. Am. J., 52:1343-1346.

Molina J.A.E., Clapp C.E., Shaffer M.J. Chichester F.W., Larson W.E. 1983. NCSOIL, a model of N and C transformation in soils; Description, calibration and behaviour. Soil Sci. Soc. Am. J., 47:85-91.

Molina J.A.E., Smith P 1997 Modelling C and N processes in soils. Advances in Agronomy, 62:253-298.

Nicolardot B., Molina J.A.E. 1994. C and N fluxes between pools of soil organic matter: model calibration with long-term field experimental data. Soil Bio. Biochem., 26:245-251.

Nicholson F.A., Chambers B.J., Mills A.R., Strachan P.J. 1997. Effects of repeated straw incorporation on crop fertiliser $\mathrm{N}$ requirements, soil mineral $\mathrm{N}$ and nitrate leaching losses. Soil Use and Management., 13:136142.

Ocio J.A., Brookes P.C., Jenkinson D.S. 1991a. Field incorporation of straw and its effects on soil microbial biomass and soil inorganic N. Soil Biol. Biochem., 23:171-176.

Ocio J.A., Martinez J., Brookes P.C. 1991b. Contribution of straw-derived $\mathrm{N}$ to total microbial biomass $\mathrm{N}$ following incorporation of cereal straw to soil. Soil Biol. Biochem., 23:655-659.

Paustina K. 1991 Modelling soil biology and biochemical processes for sustainable agriculture research. In: Pankhurst C.E., Double B.M., Gupta V.V.S.R, Grace P.R. (eds.): Soil biota. Management in Sustainable
Farming Systems, 182-193. CSIRO Information Services, Melbourne.

Powlson D.S., Jenkinson D.S., Pruden G., Johnston A.E. 1985. The effect of straw incorporation on the uptake of $\mathrm{N}$ by winter wheat. Journal of the Sci. of Food and Agric., 36:26-30.

Powlson D.S. 1990. Straw incorporation-nitrate implications. In: Burning ban, the final straw? National Agricultural Conference 28 November 1990. Royal Agricultural Society of England, National Agricultural Centre, Stoneleigh, Warwickshire.

Rijtema P.E., Kroes J.G. Some results of N simulation with the model ANIMO. Fertilzer Research, 27:189198.

Sallih Z., Pansu M. 1993. Modelling of soil C forms after organic amendment under controlled conditions. Soil Biol. Biochem., 25:1755-1762.

Smith J., Smith P., Addiscott T. 1996. Quantitative methods to evaluate and compare Soil Organic Matter (SOM) Models. In: Powlson D.S., Smith P., Smith J.U. (eds.): Evaluation of Soil Organic Matter Models. NATO ASI series 1: Global environmental changes, vol. 38 .

Smith P., Andren O., Brussard L. 1998. Soil biota and global change at the ecosystem level; describing soil biota in mathematical models. Global Change Biology, 4:773-784.

Smith J.U., Smith P., Monaghan R., Mac Donald A.J. 2002 When is a measured soil organic matter fraction equivalent to a model pool? Eur. J. of Soil Sc., 53:405-416.

Wheatly R.E., Griffiths B.S., Ritz K. 1991. Variations in the rates of nitrification and denitrification during the growth of potatoes (Solanum tuberosum L.) in soil with different $\mathrm{C}$ inputs and the effects of these inputs on soil $\mathrm{N}$ and plant yield. Biol. and Fert. of Soils, 11:157-162.

Whitmore A.P. 1991. A method for assessing the goodness of computer simulation of soil processes. Journal of Soil Science, 42:289-299.

Whitmore A.P. 1993. Nutrient supply, microbial processes and modelling. In: Mulongoy K., Merckx R. (eds): Soil organic matter dynamics and sustainability of tropical agriculture. IITA/K.U. Leuven.

Yang H.S., Janssen B.H. 2000. A mono-component model of $\mathrm{C}$ mineralization with a dynamic rate constant. Eur. J. of Soil Sci., 51:517-529. 